\title{
Article \\ Effect of Up-Converting Luminescent Nanoparticles with Increased Quantum Yield Incorporated into the Fluoropolymer Matrix on Solanum lycopersicum Growth
}

\author{
Denis V. Yanykin ${ }^{1,2, * \mathbb{D}}$, Dmitriy E. Burmistrov ${ }^{1} \mathbb{D}$, Alexander V. Simakin ${ }^{1}$, Julia A. Ermakova ${ }^{1}$ \\ and Sergey V. Gudkov 1,3,4 \\ 1 Prokhorov General Physics Institute of the Russian Academy of Sciences, 38 Vavilova St., \\ Moscow 119991, Russia; dmitriiburmistroff@gmail.com (D.E.B.); avsimakin@gmail.com (A.V.S.); \\ julia.r89@mail.ru (J.A.E.); S_makariy@rambler.ru (S.V.G.) \\ 2 Institute of Basic Biological Problems, FRC PSCBR, Russian Academy of Sciences, 2 Institutskaya St., \\ Pushchino 142290, Russia \\ 3 The Institute of Biology and Biomedicine, Lobachevsky State University of Nizhny Novgorod, Gagarin St. 23, \\ Nizhny Novgorod 603950, Russia \\ 4 Federal State Budgetary Scientific Institution "Federal Scientific Agroengineering Center VIM" (FSAC VIM), \\ Moscow 109428, Russia \\ * Correspondence: ya-d-ozh@rambler.ru
}

\section{check for}

Citation: Yanykin, D.V.; Burmistrov, D.E.; Simakin, A.V.; Ermakova, J.A.; Gudkov, S.V. Effect of Up-Converting Luminescent Nanoparticles with Increased Quantum Yield Incorporated into the Fluoropolymer Matrix on Solanum lycopersicum Growth. Agronomy 2022, 12, 108. https://doi.org/10.3390/ agronomy12010108

Academic Editor: Sara Di Lonardo

Received: 20 October 2021

Accepted: 30 December 2021

Published: 2 January 2022

Publisher's Note: MDPI stays neutral with regard to jurisdictional claims in published maps and institutional affiliations.

Copyright: (C) 2022 by the authors. Licensee MDPI, Basel, Switzerland. This article is an open access article distributed under the terms and conditions of the Creative Commons Attribution (CC BY) license (https:// creativecommons.org/licenses/by/ $4.0 /)$.

\begin{abstract}
The influence of light conversion induced by glasses coated with up-converting luminescent nanoparticles on Solanum lycopersicum cultivation was studied. Nanoparticles of $\mathrm{Sr}_{0.46} \mathrm{Ba}_{0.50} \mathrm{Yb}_{0.02} \mathrm{Er}_{0.02} \mathrm{~F}_{2.04}$ solid solution were used as the up-converting luminophore. These nanoparticles were able to transform IR radiation into visible light $\left(\lambda_{\mathrm{em}}=660 \mathrm{~nm}\right.$ with minor peaks at $545 \mathrm{~nm}$ and $\left.525 \mathrm{~nm}\right)$. By applying the "variable" chlorophyll fluorescence $(\Delta \mathrm{F})$, it was shown that the cultivation of tomatoes under the photoconversion glasses stimulated changes in the rate of plant adaptation to ultraviolet radiation. The restoration time of values of effective quantum yield of photosystem II photochemical reactions and photochemical quenching of chlorophyll fluorescence (reflecting disappearance of imbalance between photosynthetic electron transport and the utilization of NADPH) was reduced from three weeks to three days in the case of control and photoconversion films, respectively. As a result, plants grown under photoconversion glass had an increased leaf number (12.5\%), total leaf area $(33 \%)$, stem length (35\%) and chlorophyll content in the leaves (two-fold). It is assumed that an increase in the proportion of red light in the growing spectrum has a positive effect on photosynthetic activity and plant growth.
\end{abstract}

Keywords: photoconversion; up-conversion; nanomaterials; greenhouses; insufficient insolation; Solanum lycopersicum

\section{Introduction}

The Neolithic Revolution, which happened about 8000-12,000 years ago, led to the emergence of new technology-agriculture, which accelerated the growth of the world's population. First, a local acceleration of population growth was observed in the territories of the cradle of agricultural civilization. Then, farming spread throughout the planet. Over the past hundred years, due to progress in medicine, reduced mortality and increased agricultural productivity, a new acceleration in population growth has been occurred. Nowadays, there is a shortage of territories suitable for agriculture and, as a result, food manufactures. Under these circumstances, the only way out is to find ways to increase the productivity of farms, especially in regions with cold temperate and unfavorable climates [1,2]. Thereby, one of the priorities of modern biotechnology, in particular, agrophotonics, is to maintain optimal conditions for the growth of crops artificially, which is being effectively realized in modern greenhouses [3]. The lighting of plants, as close as 
possible to nature, is provided by the transparent shell. Greenhouse construction ensures an enclosed protective environment that drastically increases yield while lowering water consumption and pesticide use as compared to conventional farming [4-6], adds more growth cycles per year and allows growing thermophilic plant species in colder climates.

Unfortunately, there is a strong shortage of sunlight in northern and even temperate latitudes from autumn to spring. Currently, the most common approach to solve this problem is the additional lighting of plants using artificial light sources. However, the need for artificial lighting leads to a significant increase in energy consumption in comparison to traditional farming [7-9]. The usage of photoconversion coatings of greenhouse glass is an example of technologies that allow increasing the productivity of grown plants and reduce costs. These materials are capable of converting light from one spectrum region to another. The conversion of sunlight only makes sense in the case of transforming photons that are little used by plants in photosynthesis (or harmful to plants) into photons that are effectively used in photosynthesis. For example, the conversion of ultraviolet or green light into blue or red light can be applied.

Luminescent materials (metal complexes, semiconductors, nanoparticles, fluorescent proteins, organic dyes) are widely applied in different fields: optics, biomedicine, environmental purification, agriculture, etc. [10-16]. However, one of the major difficulties of the practical application of photoconversion devices is the lack of perfect materials. Coatings, which contained organic fluorophores, burn out rapidly. Fluorophores based on rare-earth metals and their compounds (for example, europium) have increased stability but a very low quantum yield of conversion [17-21]. Nanoparticles with plasmon or exciton emission (cadmium-selenium, zinc-sulfur, etc.) [22-25] are hardly incorporated into polymer matrices and are very sensitive to reactive oxygen species formed during the functioning of the luminophore. A perfect photoconversion system must have the following features: (1) maximum solar spectrum transmittance in a spectrum range that is critical for the efficiency of photosynthesis; (2) maximum solar spectrum absorption in other ranges and high quantum yield of re-emission; (3) suitable surface modification to satisfy the requirements for targeted photoreactions; (4) high chemical and photostability; (5) minimization of reabsorption losses of luminescence. Although, in practice, it is difficult to optimize materials to meet all these requirements, modern studies are focused on the perfection of photoconversion coatings. In several works [26-28], we have developed highly resistant and vapor-proof photoconversion films on the basis of fluoropolymer and nanoparticles as well as quantum dots, which are capable of the effective photoconversion of UV and violet radiation into blue and red light and of providing more favorable light conditions for plant growth. Despite the difficulties, photoconversion technologies have great potential to maintain the plant's growth rate and quality under variable weather conditions while additional energy consumption is absent.

Practically all luminescent materials applied in greenhouses glasses act as downshifted emitters (Stokes-shifted, when each emitted photon has lower energy than the absorbed one). These materials use ultraviolet, violet and green light, the proportion of which is not so high in the solar spectrum near the earth's surface. A huge number of photons have a wavelength of $>700 \mathrm{~nm}$, and their conversion to the PAR range (photosynthetically active radiation) is a promising and interesting challenge. A few luminophores are capable of emitting photons with higher energy than those used for excitation (anti-Stokes shifted or up-conversion luminescence). The development of up-converting luminophores that convert near-infrared radiation (NIR) into visible light is one of the relatively new scientific trends. Such luminophores were proposed in the mid-20th century $[29,30]$. Typically, up-converting nanoparticles are composed of three parts: a sensitizer, an activator and a matrix. Sensitizers absorb energy and transfer energy to activator ions, which are used as the center of emission. The matrix is not usually involved in energy transfer but acts as a stabilizing ion. At present, it is considered promising to use combinations of rare-earth elements (REE, for example, $\mathrm{Yb}^{3+}: \mathrm{Er}^{3+}: \mathrm{Tm}^{3+}$ and $\mathrm{Ho}^{3+}$ ions) to create visible light sources. $\mathrm{Yb}^{3+}$ is used as a sensitizer due to its simple energy levels' structure and 
large absorption cross-section [31], while $\mathrm{Er}^{3+}, \mathrm{Tm}^{3+}$ and $\mathrm{Ho}^{3+}$ ions are used as activators $[32,33]$. Strontium fluoride is usually used as a matrix, which provides a high quantum yield of up-conversion [34,35]. It is worth noting that fluorides have some advantages in comparison with oxides, chlorides and chalcogenides [36]. It was assumed that $\mathrm{a} \mathrm{BaF}_{2}$ single crystal as a matrix could further increase the efficiency of the up-conversion [37]. At present, the materials with the highest quantum yields of up-conversion are $\mathrm{BaF}_{2}$ single crystals co-doped with $\mathrm{Yb}^{3+}(3 \mathrm{~mol} \%)$ and $\mathrm{Er}^{3+}(2 \mathrm{~mol} \%), \mathrm{NaYF}_{4}: \mathrm{Yb}^{3+}, \mathrm{Er}^{3+}$ and $\mathrm{NaGdF}_{4}$ : $\mathrm{Yb}^{3+}, \mathrm{Er}^{3+}$ with a quantum yield of $10 \%, 11 \%$ and $14 \%$, respectively [37-39].

Plants are able to use light in the so-called photosynthetically active radiation range, which is wavelengths of $400-700 \mathrm{~nm}$. Changes in the spectral composition are known to affect plant morphology, physiology and development, particularly processes of photosynthesis and secondary metabolism [40-42]. The light action spectrum for photosynthesis was described in detail by McCree [43]. It was shown that in light-limited conditions, red light was more optimal for the intensification of photosynthesis. However, red illumination alone is not sufficient for optimal photosynthesis and plant growth. Other light wavelengths can further intensify photosynthesis. Under red illumination, "red light syndrome" can be formed - the state with changed plant phenotype, deviant biochemistry and gene expression. Additional illumination with blue light can prevent the syndrome [44]. Blue light also promotes improving access to $\mathrm{CO}_{2}$, driving transpiration and nutrient uptake due to stomatal opening [45-48]. Far-red light can increase plant stress resistance. Green light can penetrate the leaf deeper than red and blue and be used by lower-tier leaves (as well as by tissues in the depth of the leaf) that are out of reach for red and blue light [49-51].

In this work, we investigated the effects of up-converting luminescent nanoparticles incorporated into fluoropolymer films coated on glasses on the growth of agricultural plants. $\mathrm{Sr}_{0.46} \mathrm{Ba}_{0.50} \mathrm{Yb}_{0.02} \mathrm{Er}_{0.02} \mathrm{~F}_{2.04}$ (UCL) nanoparticles were used as the up-converting luminophore, which can convert IR into visible light. We assume that coating greenhouse glasses with up-converting luminescent nanoparticles may be successfully used to improve a lack of natural light and achieve an increase in plant biomass.

\section{Materials and Methods}

\subsection{Preparation of Photoluminophore Nanoparticles and Investigation of Its Properties}

The synthesis of up-conversion nanopowders with the nominal composition $\mathrm{Sr}_{0.46} \mathrm{Ba}_{0.50} \mathrm{Yb}_{0.02} \mathrm{Er}_{0.02} \mathrm{~F}_{2.04}$ was carried out by co-precipitation from aqueous nitrate solutions at ambient conditions according to a previously published protocol [52]. A mixture of nitrate solutions $(0.08 \mathrm{M})$ was dropwise added to an ammonium fluoride solution $(0.16 \mathrm{M})$ taken with a $7 \%$ excess from stoichiometry. Afterwards, the produced suspension was stirred for $2 \mathrm{~h}$. After settling, the precipitates were washed with a dilute solution of ammonium fluoride with controlled washing purity from nitrate ions by a qualitative reaction with diphenylamine. Then, the precipitate was dried sequentially at $45{ }^{\circ} \mathrm{C}$ in air and at $600{ }^{\circ} \mathrm{C}$ in a platinum crucible for $1 \mathrm{~h}$ at a heating rate of 10 degrees $/ \mathrm{min}$.

To manufacture the photoconversion composites, a $7 \%$ solution of nanoparticles in acetone was used. The solution of nanoparticles was mixed with the liquid component of the fluoroplate polymer in a ratio of 1/100. Fluoroplast-32L (St. Petersburg Kraski, Russia) served as the basis for obtaining the polymer varnish. The mixture was stirred for $10 \mathrm{~min}$ until a homogeneous mass was obtained. To apply the photoconversion coating to the glass, a spray gun was used. Thus, a photoconversion film (PCF) containing luminescent nanoparticles was formed on the glass surface.

X-ray pattern diffraction (XRD) was performed on a BRUKER D8 ADVANCE diffractometer (Billerica, MA, USA) with $\mathrm{CuK} \alpha$-radiation. The unit cell parameters $(a)$ were calculated using POWDER 2.0 software (Moscow State University, Russia). The morphology and particle size of nanoparticles were determined with the scanning electron microscope Carl Zeiss NVision 40 (Zeiss AG, Oberkochen, Germany) (ImageJ software for photos analysis) connected with the Oxford Instruments XMAX $\left(80 \mathrm{~mm}^{2}\right)$ energydispersion analysis set-up (Oxford Instruments $p l c$, Abingdon, UK). The hydrodynamic 
diameter and zeta potential distribution of nanoparticles were measured with Zetasizer Ultra (Malvern Panalytical, Malvern, UK). The up-conversion luminescence spectra in the visible range were recorded using fiber-optic spectrometer USB2000 (OceanOptics, Orlando, FL, USA). The sample was placed inside the integrating sphere Cintra 4040 (GBC Scientific, Braeside, Victoria, Australia) and irradiated using a $50 \mathrm{~mW}$ IR light diode, which emits in the region of 960-985 $\mathrm{nm}$ with a maximum of $975 \mathrm{~nm}$. The up-conversion emission and scattered laser radiation were collected by the fiber and delivered to spectrometer.

\subsection{Plant Material and Growth Conditions}

Solanum lycopersicum plants (determinate cultivar "Balkonnoe Chudo") were used in the study. Before experiments, all the plants were grown in a 16-h-light/8-h-dark cycle at $25-26{ }^{\circ} \mathrm{C}$ and at a weak light intensity (PPFD $(400 \mathrm{~nm}-700 \mathrm{~nm})$ and PFD $(350 \mathrm{~nm}-800 \mathrm{~nm})$ were $70 \mu \mathrm{mol}$ photon $\mathrm{s}^{-1} \mathrm{~m}^{-2}$ and $140 \mu \mathrm{mol}$ photon $\mathrm{s}^{-1} \mathrm{~m}^{-2}$, respectively). On the seventh leaf stage, both experiment and control plants were placed under glasses coated with fluoroplate polymer with or without photoconversion nanoparticles, respectively. A UVA component $\left(\lambda=370 \mathrm{~nm}, \mathrm{PFD}=10 \mu \mathrm{mol}\right.$ photon $\left.\mathrm{s}^{-1} \mathrm{~m}^{-2}\right)$ was added to the illumination spectrum.

The leaf area was determined using the GreenImage software developed by our team [26]. The content of chlorophyll in leaves was determined with chlorophyll content meter CL-01 (Hansatech Instruments, Norfolk, UK). The number of leaves and the stem length were determined manually. Light intensity was measured using PG200N Spectral PAR Meter (UPRtek, Zhunan, Miaoli, Taiwan).

\subsection{Chlorophyll Fluorescence (ChlF) Measurement}

Before experiments (treatments and measurements), both tomato plants and leaves were kept for $60 \mathrm{~min}$ in the dark at a temperature of $25-26^{\circ} \mathrm{C}$. The kinetics of photoinduced changes of the ChlF yield $(\Delta \mathrm{F})$ related to the photoreduction in the primary electron acceptor, $\mathrm{Q}_{\mathrm{A}}$, was measured on a non-cut leaf at room temperature with the DUAL-PAM-100 fluorometer (Waltz, Eichenring, Effeltrich, Germany). To measure the maximum quantum yield of PS2 photochemistry $\left(\left(\mathrm{Fm}-\mathrm{F}_{0}\right) / \mathrm{Fm}\right.$, where $\mathrm{F}_{0}$ is the initial fluorescence value and $\mathrm{Fm}$ is the maximum fluorescence value) and ChlF parameters after light adaptation (10 min, $\lambda=625 \mathrm{~nm}, 250 \mu \mathrm{mol}$ photon $\mathrm{s}^{-1} \mathrm{~m}^{-2}$ ), the samples were illuminated with a saturating $500-\mathrm{ms}$ flash $\left(\lambda=625 \mathrm{~nm}, 12,000 \mu \mathrm{mol}\right.$ photon $\left.\mathrm{s}^{-1} \mathrm{~m}^{-2}\right)$. The calculation of the ChlF parameters was performed using DualPAM Software [53].

To study the kinetics of PS2 photoinhibition, leaves were incubated overnight in the dark in the absence and in the presence of $1 \mathrm{mM}$ lincomycin to inhibit protein synthesis in chloroplasts. Light treatment was implemented in the growth chamber, and illumination under which the plants grew was used as the inhibitory light. To prevent desiccation, the cut ends of the leaf stalks were submerged in water during the light treatment $(90 \mathrm{~min}$ ). $\Delta \mathrm{F}$ was measured before and after the light treatment to estimate the relative amount of active reaction centers of PS2 (PS2 RCs) after the light treatment. The values obtained for dark-adapted samples not treated with light were taken as $100 \%$. Rate constants of photoinhibition were calculated according to the equation $\mathrm{k}(\mathrm{pi})=\ln \left[\mathrm{At}_{1} / \mathrm{At}_{2}\right] /\left(\mathrm{t}_{2}-\mathrm{t}_{1}\right)$, where $A t_{1}$ and $A t_{2}$ are the relative amounts of active PS2 reaction centers at the time $t_{1}$ and $t_{2}$, respectively [54-56].

\subsection{Statistical Analysis}

To determine statistically significant differences between plant groups, one-way analysis of variance (ANOVA) followed by post hoc comparisons by Tukey's test and Student's $t$-test for independent means were performed. The difference was considered significant if $p \leq 0.05$. 


\section{Results}

\subsection{Characteristics of Nanosized Fluorophores}

The photoluminescence spectra of $\mathrm{Sr}_{0.46} \mathrm{Ba}_{0.50} \mathrm{Yb}_{0.02} \mathrm{Er}_{0.02} \mathrm{~F}_{2.04}$ nanoparticles in acetone in the PAR range are shown in Figure 1A. Infrared excitation $(976 \mathrm{~nm})$ of the UCL lead to luminescence with typical bands of the ion pair $\mathrm{Er}^{3+} / \mathrm{Yb}^{3+}: 1.87 \mathrm{eV}$ (about $660 \mathrm{~nm}$ ), $2.27 \mathrm{eV}$ $(545 \mathrm{~nm})$ and $2.36 \mathrm{eV}$ (525 nm) (Figure 1A, curve 1). These data correlate well with previous data obtained in luminophores with a comparable structure [35,37,57-61]. Weak emission at $850 \mathrm{~nm}$ (outside the PAR range) is not shown. It should be noted that the data presented in Figure 1A are demonstrative and not intended for estimating the quantum yield of up-photoconversion with statistical accuracy.

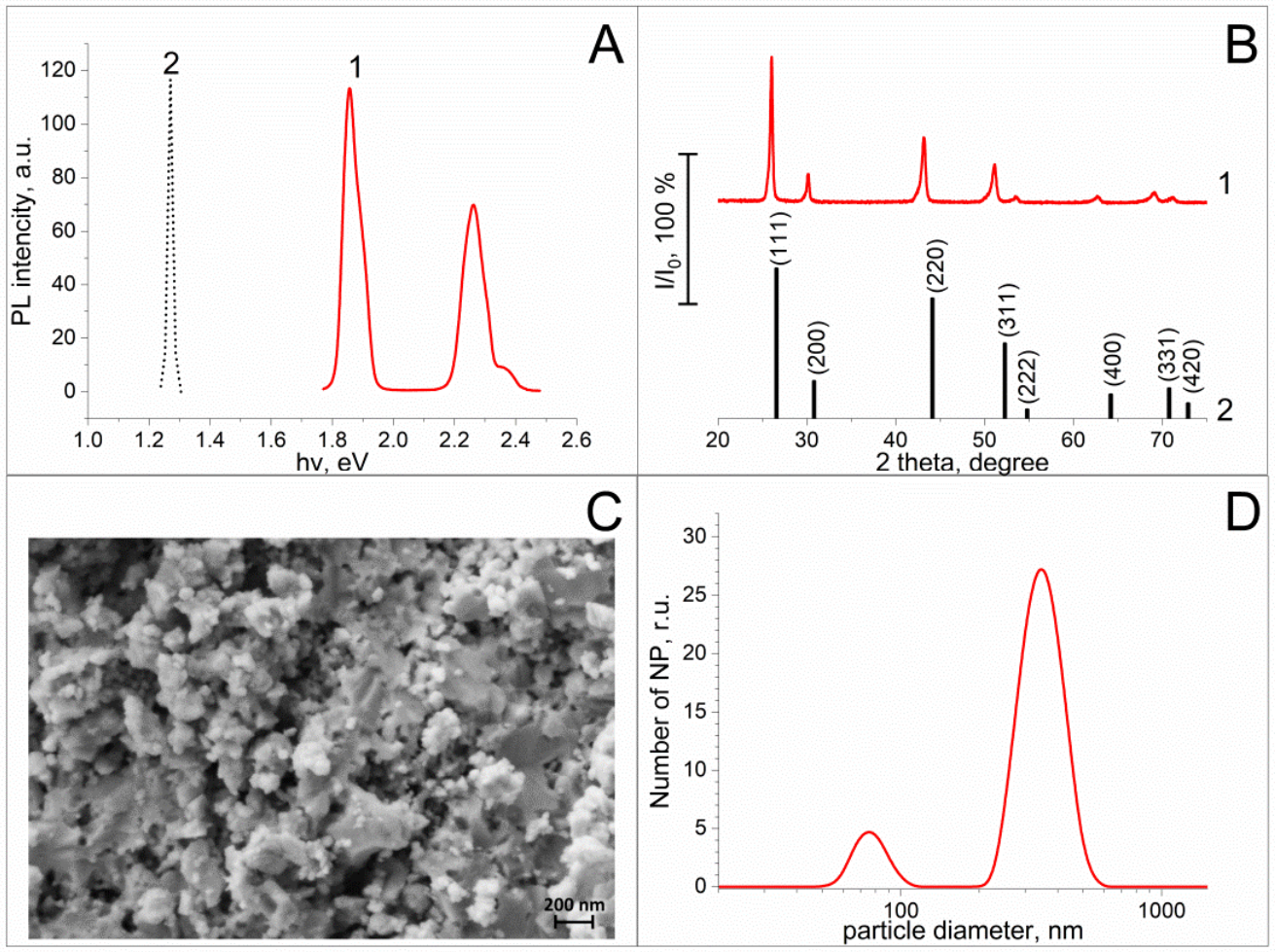

Figure 1. Characteristics of nanosized fluorophores $\left(\mathrm{Sr}_{0.46} \mathrm{Ba}_{0.50} \mathrm{Yb}_{0.02} \mathrm{Er}_{0.02} \mathrm{~F}_{2.04}\right)$. (A) Photoluminescence (PL) (curve 1) of the nanoparticles in acetone in the PAR range, which was excited with IR light diode (curve 2). (B) X-ray diffraction pattern for the nanoparticles after heat treatment at $600{ }^{\circ} \mathrm{C}$ (1) and JCPDS \#06-0262 for $\mathrm{SrF}_{2}$ (2). (C) SEM images for samples after a heat treatment at $600{ }^{\circ} \mathrm{C}$. (D) Size distribution of nanoparticles (NP) of fluorophores obtained using dynamic light scattering.

The XRD pattern of $\mathrm{Sr}_{0.46} \mathrm{Ba}_{0.50} \mathrm{Yb}_{0.02} \mathrm{Er}_{0.02} \mathrm{~F}_{2.04}$ solid solution after heat treatment at $600{ }^{\circ} \mathrm{C}$ confirms its pure and single-phase (Figure 1B). The formation of a single-phase powder with a fluorite structure (JCPDS \#06-0262, $a=5.800 \AA$ ) was revealed (compare curve 1 and curve 2). The scanning electron microscopy image for $\mathrm{Sr}_{0.46} \mathrm{Ba}_{0.50} \mathrm{Yb}_{0.02} \mathrm{Er}_{0.02} \mathrm{~F}_{2.04}$ samples shown in Figure $1 \mathrm{C}$ indicates that the heat treatment leads to the formation of rounded particles with a mean size of $72 \mathrm{~nm}$ and their agglomerates with a mean size of $242 \mathrm{~nm}$. The dynamic light scattering method confirmed this observation (Figure 1D). The powder contains two pools of particles: primary particles with an average nanoparticle size ranging from 55 to $100 \mathrm{~nm}$ and agglomerates of primary particles. Note that most of the particles are presented in the form of agglomerates. Using Energy-dispersive $\mathrm{X}$-ray spectroscopy, a real composition of solid solution powder was determined as $\mathrm{Sr}_{0.533} \mathrm{Ba}_{0.415} \mathrm{Yb}_{0.026} \mathrm{Er}_{0.026} \mathrm{~F}_{2.052}$. For implantation into a polymer film, nanoparticles were mixed with the liquid component of the fluoroplate polymer in a ratio of 1/100 in acetone and then distributed on the glass surface. 


\subsection{Influence of Photoconversion Glasses on Plant Grow}

To simulate average solar lighting on a cloudy day, all the plants were grown under weak illumination. The photosynthetic photon flux density (PPFD, 400-700 nm) was $70 \mu \mathrm{mol}$ photon $\mathrm{s}^{-1} \mathrm{~m}^{-2}$ and was half of the total photon flux density measured from $350 \mathrm{~nm}$ to $800 \mathrm{~nm}$. On the seventh leaf stage, glasses coated with the fluoraplate polymer with or without photoconversion nanoparticles were installed above plants. Immediately before the start of the experiment, a UVA component $(\lambda=370 \mathrm{~nm}, \mathrm{PFD}=10 \mu \mathrm{mol}$ photon $\mathrm{s}^{-1} \mathrm{~m}^{-2}$ ) was added to the illumination spectrum. Note that control glasses coated with fluoroplate polymer (in the absence of nanoparticles) decreased the light intensity in the PAR region by $18 \%$.

It was shown that the presence of photoconversion films above the plants had a positive effect on plant growth (Figure 2). The results of monitoring the stem length, number and area of leaves and relative chlorophyll content are shown in Figure 3. Chlorophyll content in the control group of plants practically did not change during the experiment. Conversely, under the photoconversion films, a rapid increase in the chlorophyll content in the leaves was observed from the fifth to tenth day (Figure 3A). Thus, during the experiment, chlorophyll content enhanced from $6.4 \pm 0.3$ r.u. to $8.7 \pm 1.0$ r.u. The increase in leaf area was affected by the presence of photoconversion glasses above the plants (Figure 3B). If under control glasses, the leaf area increased from about $22.9 \pm 3.8 \mathrm{~cm}^{2}$ to $89.7 \pm 9.5 \mathrm{~cm}^{2}$, then under PCF at the end of the experiment, the leaf area reached $119.8 \pm 16.4 \mathrm{~cm}^{2}$. Under control films, the number of leaves was increased from $7.0 \pm 0.3$ leaves per one plant to $11.7 \pm 0.5$ leaves per one plant, whereas under photoconversion films, the number increased to $14.7 \pm 1.5$ leaves per one plant (Figure 3C). Statistically significant differences in the number of leaves between both groups were found on the tenth-twelfth day of the experiment. Thus, an increase in the number of leaves consisted of $40 \%$ and $110 \%$ for control and experiment plants, respectively. A more rapid increase in stem length was found in plants growing under PCF (Figure 3D). However, statistically significant differences between both plant groups were found only at the end of the third and fourth weeks of the experiment (and in the case of leaf area). Thus, films containing photoconversion nanoparticles accelerated the growth and development of the tomatoes.

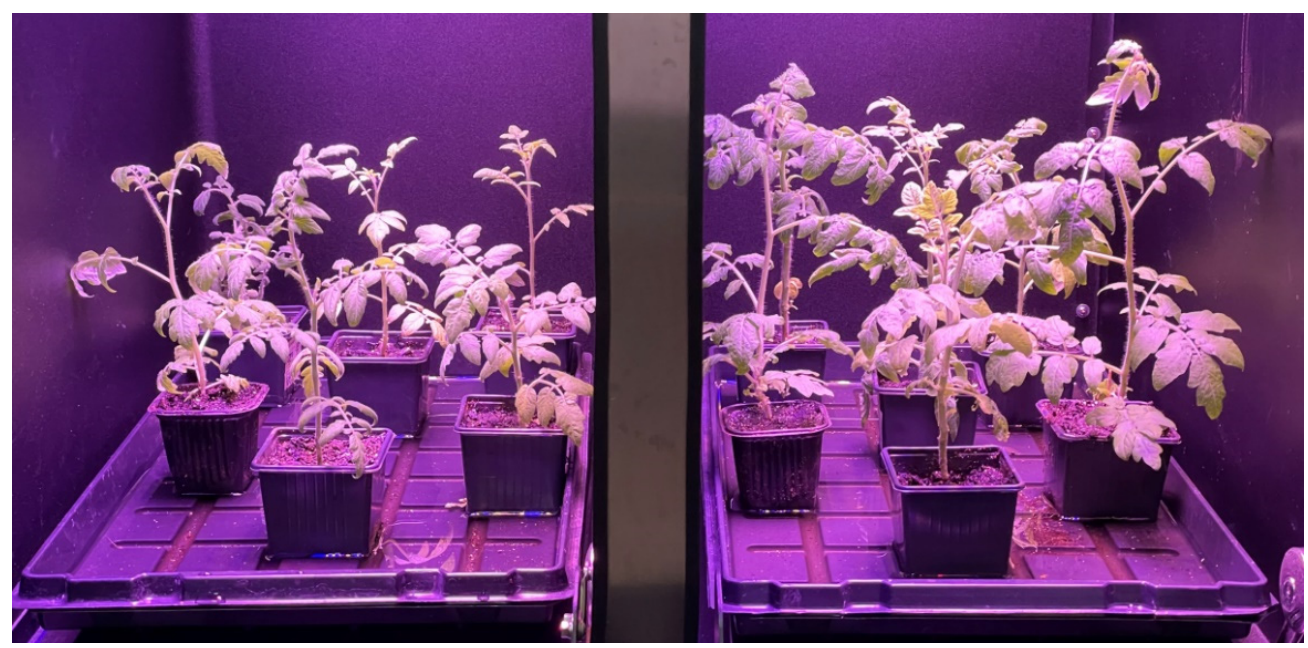

Figure 2. Photo of tomatoes grown under glasses coated with fluoroplate polymer without (left) or with (right) photoconversion nanoparticles. 

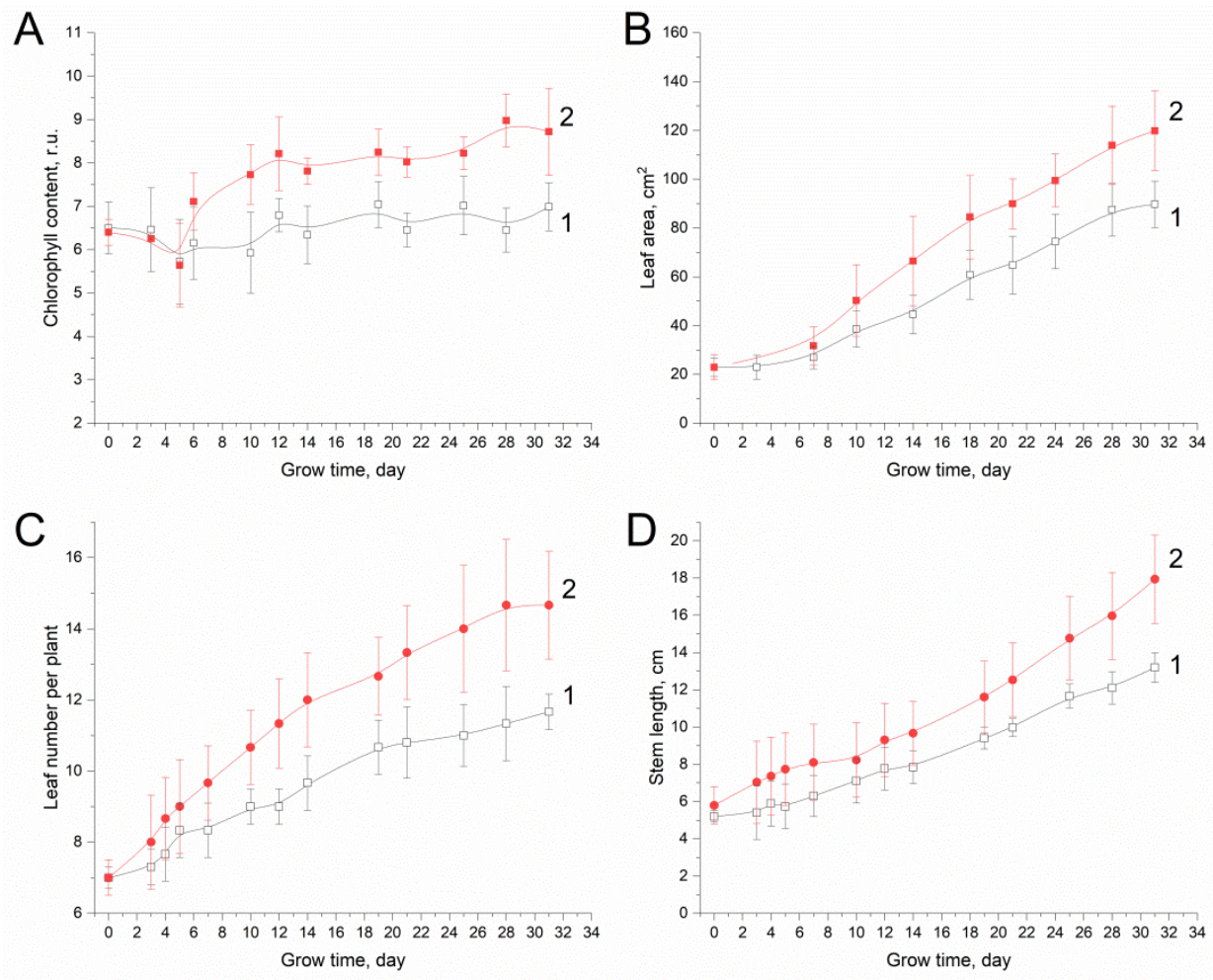

Figure 3. Dependence of relative chlorophyll content (A), total area (B) and number (C) of leaves and stem length (D) on grow time of plants under glasses coated with fluoroplate polymer without (1) or with (2) photoconversion nanoparticles. The data are the means of at least 11 measurements, with the standard error of the mean. Relative chlorophyll content value is the mean of 4-10 measurements on at least 11 plants.

To explain this, we have performed an analysis of the light-induced changes in the ChlF (Figure 4). The maximum quantum yield $\left(\Delta \mathrm{F} / \mathrm{F}_{\mathrm{m}}\right)$ in the leaves of dark-adapted plants before the experiment was equal to 0.82 and practically did not change within the experiment (Figure 4A). It is known that light energy absorbed by the photosynthetic antenna can distribute between three processes capable of utilizing the excitation energy. These processes are reflected in quenching the chlorophyll fluorescence: so-called photochemical quenching, non-photochemical quenching (NPQ) and non-regulated heat dissipation and fluorescence emission (NO). The effective quantum yield of photosystem II photochemical reactions Y(II) correlated well with photochemical quenching in leaves of both plant groups and decreased within the first week from 0.28 to 0.11 (Figure 4B), which indicates some imbalance between photosynthetic electron transport and the utilization of NADPH reduction in plants. Afterward, Y (II) increased and gradually reached the initial values. In control plants, Y(II) increased slowly and reached the initial values by the end of the fourth week of the experiment. On the contrary, in plants growing under PCF, Y(II) increased rapidly (initial Y(II) values were reached within a few days, and further practically does not change). The first five days of the experiment were accompanied by a moderate increase in $\mathrm{Y}(\mathrm{NPQ})$ from 0.35 to 0.45 in control plants and by a more significant increase in $Y(N P Q)$ to 0.5 in experiment plants (Figure 4C). One week after that, $\mathrm{Y}(\mathrm{NPQ})$ decreased to initial values and did not change much subsequently. Different amplification of Y(NPQ) in the control and experimental groups may be a consequence of the different efficiency of protective mechanisms during the adaptation of plants to changed lighting conditions. It is important to mark that the proportion of uncontrolled dissipation of absorbed light energy practically did not change in plants growing under photoconversion films. At the same time, in plants growing under common films, $\mathrm{Y}(\mathrm{NO})$ increased from $38 \%$ to practically $50 \%$ during the first week of the experiment and then relaxed to values observed before the start of the experiment within two weeks (Figure 4D). The development of the parameters photochemical 
$\left(\mathrm{q}_{\mathrm{L}}\right)$ and non-photochemical $\left(\mathrm{q}_{\mathrm{N}}\right)$ quenching (Figure 4E,F) in plants correlates well with the data described above and can reflect both the partial inhibition of photosynthesis and the activation of heat dissipation of absorbed light energy at the first week of the experiment. However, the activation of heat dissipation in both plant groups had different mechanisms: if in control plants, it was provided by both controlled and non-controlled dissipation, then in experiment plants, non-regulated heat dissipation was not enhanced.
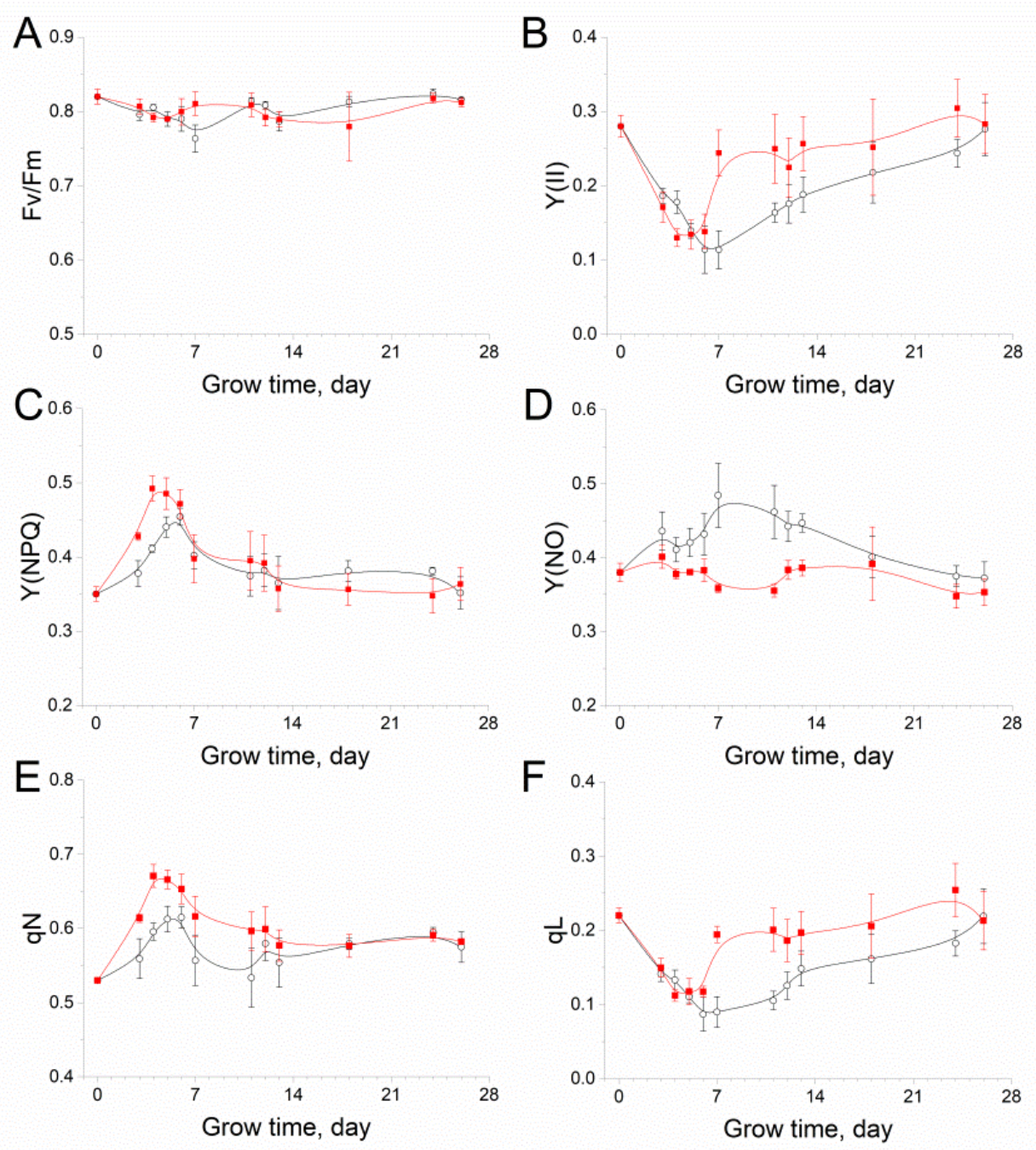

Figure 4. Dependence of maximal Fv /Fm (A) and effective Y(II) (B) quantum yield of photosystem II photochemistry, quantum yield of light-induced non-photochemical quenching of ChlF (Y(NPQ)) (C), quantum yield of nonregulated heat dissipation and fluorescence emission $(\mathrm{Y}(\mathrm{NO}))(\mathrm{D})$, photochemical (qN) (E) and non-photochemical (qL) (F) ChlF quenching on grow time of plants under glasses coated with fluoroplate polymer with (closed symbols) or without (opened symbols) photoconversion nanoparticles. The adaptation of samples to actinic light was carried out for $10 \mathrm{~min}$. Measurements were taken at room temperature. The data are the means of at least 3 measurements, with the standard error of the mean.

It is known that under the illumination of the leaves, two oppositely directed processes occur-photoinactivation of the photosynthetic apparatus and its photorecovery. To estimate the damaging effect of light passed through control and photoconversion films, we calculated the rate constant of photoinhibition ( $\mathrm{k}(\mathrm{pi}))$ of photosynthetic activity. For this aim, leaves were treated with $1 \mathrm{mM}$ lincomycin, an inhibitor of the repair process. The measurements were also performed on untreated leaves. Rate constants of photoinhibition in leaves without lincomycinare were close to zero, which indicates that 
the recovery processes prevail over the damaging processes under these light conditions. Using lincomycin-treated leaves, it was shown that $\mathrm{k}(\mathrm{pi})$ under PCF was $20 \%$ higher than under common film (Table 1).

Table 1. Rate constants of photoinhibition $(\mathrm{k}(\mathrm{pi}))$ in tomato leaves under common and photoconversion films. The data are the means of at least three measurements.

\begin{tabular}{|c|c|c|}
\hline \multirow{2}{*}{ Glass Coating Type } & \multicolumn{2}{|c|}{$k(\mathrm{pi}), \mathrm{s}^{-1} \times 10^{-5} \pm \mathrm{se}$} \\
\hline & $1 \mathrm{mM}$ Lincomycin & Without Lincomycin \\
\hline Common film & $6.88 \pm 0.69^{a}$ & 0 \\
\hline Photoconversion film & $8.29 \pm 0.54^{b}$ & 0 \\
\hline
\end{tabular}

\section{Discussion}

For several decades, scientists have traveled a long way in the development of photoconversion coatings for agricultural applications: from (i) short-lived fluorophores based on polyethylene and organic dyes through (ii) relatively stable fluorophores based on rare-earth compounds, which, however, have a low quantum yield, to the (iii) creation of materials based on complex nanosized fluorophores. In the present work, we have successfully applied an approach based on the creation of photoconversion materials for agriculture based on complex nanosized luminophores that are capable of Anti-Stokes emission, the so-called up-conversion luminescence, where emitted photons have higher energy than the absorbed ones. Despite the low quantum efficiency (usually 4-6\%) in comparison with down-shifting luminophores (10-30\%), the use of up-conversion coatings can be justified when growing plants. For the growth and development of plants, not only the intensity of illumination plays an important role but also the spectral composition. For example, a change in red/far-red ratio can activate the phytochrome system that, in turn, can lead to intensification of photosynthesis, increase stress resistance and acceleration of plant growth [62-64]. Moreover, changes in light quality are known to have an influence on processes of photosynthesis, secondary metabolism and ultimately on plant morphology, physiology and development.

It was generally accepted that plants could utilize light with wavelengths $400-700 \mathrm{~nm}$ (so-called PAR region). However, PAR can contain less than half of the photons reaching the Earth's surface, and plants practically do not use photons with lower energy than the PAR range. This knowledge should be applied in the development of photoconversion technologies in agriculture in temperate and arctic latitudes. It is known that in weak light conditions, red light has a stronger effect on the intensification of photosynthesis. In the present work, we used a photoconversion cover containing $\mathrm{Sr}_{0.46} \mathrm{Ba}_{0.50} \mathrm{Yb}_{0.02} \mathrm{Er}_{0.02} \mathrm{~F}_{2.04}$ nanoparticles, which convert a part of IR photons into visible light (red $(655 \mathrm{~nm})$ and partially green (545 $\mathrm{nm}$ and $525 \mathrm{~nm})$ ). In comparison with down-shifting analogue $[25,65,66]$, our luminophores have less quantum efficiency. However, these nanoparticles are very efficient phosphors among up-conversion luminophores [37]. Moreover, this type of nanoparticles can take part in the conversion of UV to green and red light $[35,37]$, which only increases their value for applications in greenhouses.

Figure 2 demonstrates that plants under PCF have accelerated growth and development: the increase in leaf number and their total area are $25 \%$ and $35 \%$ in comparison with control; the stem becomes $30 \%$ higher. Moreover, under PCF, an increase in chlorophyll content from $6.4 \pm 0.3$ r.u. to $8.7 \pm 1.0$ r.u. was observed. Measured values of the relative chlorophyll content correspond to $20-25 \mathrm{mg} \mathrm{Chl} \mathrm{(g} \mathrm{FW)}{ }^{-1}$ and $40 \mathrm{mg} \mathrm{Chl} \mathrm{(g} \mathrm{FW)}^{-1}$, respectively [67], which can reflect the 2-fold difference in chlorophyll content in the leaves of two plant groups. Analogous results were obtained earlier [28] when the effect of red down-shifting luminophore on the development of agricultural plants was studied. In the present work, the down-shifting red luminophore was replaced with an up-converting one, and the replacement did not significantly change the efficiency of photoconversion coats. 
As mentioned above, only a negligible proportion of absorbed energy is converted into luminescence in the PAR region because the quantum yield of up-conversion is small and only a little part of UV or IR is absorbed by nanoparticles. Thus, a significant part of light energy is passed through photoconversion films or dissipated as heat. However, in this study, as well as in plenty of other works [25-28,64-66,68-82], despite a subtle increase in light intensity in the PAR region, a significant positive effect of photoconversion coatings on plants growth was shown. However, the apparent paradox can be explained. The nanosized particles we use are capable of absorbing and scattering ultraviolet radiation and, therefore, acting as a protectant against UV. However, the addition of UVA (10 $\mu$ mol photon $\mathrm{s}^{-1} \mathrm{~m}^{-2}$ ) in the growth light spectrum equally affected the photochemistry of both groups of plants in the first week of the experiment (Figure 3B), which does not support (and does not refute) this assumption. Nevertheless, the increase in $\mathrm{Y}(\mathrm{NO})$ was observed only in the control plant group, which indicated some damage to the photosynthetic apparatus. Our data also indicate that plants are stressed under changed light conditions (addition of UVA in the light spectrum), which is reflected in the inhibition of plant growth in the first days (Figure 3B,D). According to other data [83], UVA supplementation stimulates biomass production and enhances secondary metabolite accumulation. It is known that a change in the red/far-red ratio can lead to the activation of the phytochrome system that, in turn, could intensify photosynthesis, increase stress resistance and accelerate plant growth [62-64]. Luminescent and scattered light (nanoparticles not only absorb and re-emit light but also scatter it) spreads in all directions. It is believed that such lighting illuminates the plants more evenly, which has a beneficial effect on their development. Under weak light conditions, the contribution of luminophore-emitted red light can be significant for plant growth. It was shown that photoconversion films, which are emitted in the red region, could stimulate changes in the content of phytohormones [84]. Photoconversion films affected the number of soil microorganisms, which had a positive effect on plants' growth $[72,85]$. Over time, the plants adapted to the changed conditions, and photoconversion films accelerated this process. The reduced rate of recovery of photochemical quenching of ChlF (qL, Figure 4F) in control plants may be caused by the lower activity of the Calvin cycle. An increased proportion of $\mathrm{Y}(\mathrm{NO})$ (energy dissipation pathway independent of $\Delta \mathrm{pH}$, violaxanthin cycle and excitation energy redistribution between two photosystems) can be due to the disturbance in photosynthetic water oxidation. The high rates of nonradiative charge recombination in photosystem II were observed after damage to the water oxidizing complex [86].

On the one hand, our data indicate that spectral changes (as well as the alteration in the red light/far-red light ratio) induced by PFC promote the increase in the plant's stress resistance and intensification of photosynthesis and plant growth (compare the data shown in Figures 2 and 3). On the other hand, our data indicate that under the photoconversion films, plants are exposed to stronger photoinhibition than under control films (Table 1). However, this did not lead to both the suppression of plant growth and photoinhibition in the absence of an antibiotic. It can be assumed that either the plants themselves have sufficient potential for recovery after photodamage or the photoresistance increases due to spectral changes. It is known that plants grown under low light and exposed to high light are poorly acclimated and experience photoinhibition [87]. The increase in the photoinhibition degree under PCF may be due to a magnification of the PAR intensity induced by light conversion. Additional light absorption by photosynthetic antennae complexes should lead to the increase in the possibility of damage to the D1 protein [88,89]. (D1 protein is the main target for photodamage in plants.) In the case of the inhibition of the D1 protein synthesis de novo by lincomycin, the intensification of photoinhibition becomes visible. These findings can reflect growth in the PAR intensity under photoconversion glasses. 


\section{Conclusions}

Nowadays, the highest quantum yields of photoconversion in up-conversion materials reach $14 \%$, and $\mathrm{Sr}_{0.46} \mathrm{Ba}_{0.50} \mathrm{Yb}_{0.02} \mathrm{Er}_{0.02} \mathrm{~F}_{2.04}$ nanoparticles are among them. These nanoparticles may be successfully used in greenhouses due to IR conversion into visible light that, in turn, can activate photosynthesis and plant growth. The obtained results can be used to develop photoconversion coatings for agriculture, which is in need of technology to increase yields.

Author Contributions: Conceptualization, D.V.Y. and S.V.G.; methodology, D.V.Y. and S.V.G.; formal analysis, D.V.Y. and D.E.B.; investigation, D.V.Y., D.E.B., A.V.S. and J.A.E.; writing-original draft preparation, D.V.Y.; writing - review and editing, D.V.Y. and S.V.G.; funding acquisition, S.V.G. All authors have read and agreed to the published version of the manuscript.

Funding: This research was funded by a grant from the Ministry of Science and Higher Education of the Russian Federation for large scientific projects in priority areas of scientific and technological development (subsidy identifier 075-15-2020-774).

Institutional Review Board Statement: Not applicable.

Informed Consent Statement: Not applicable.

Acknowledgments: The authors are thankful to S.V. Kuznetsov, A.A. Alexandrov and V.V. Voronov (Prokhorov General Physics Institute of the Russian Academy of Sciences, Moscow) for valuable discussions. The authors are grateful to the Center for Collective Use of the GPI RAS for the equipment provided.

Conflicts of Interest: The authors declare no conflict of interest.

\section{References}

1. Roser, M.; Ritchie, H.; Ortiz-Ospina, E. World Population Growth; Our World in Data: Oxford, UK, 2013.

2. Hayami, Y.; Ruttan, V.W. Population Growth and Agricultural Productivity. In Technological Prospects and Population Trends; Espenshade, T.J., Stolnitz, G.J., Eds.; Routledge: New York, NY, USA, 2020; pp. 11-69.

3. Gudkov, S.V.; Andreev, S.N.; Barmina, E.V.; Bunkin, N.; Kartabaeva, B.B.; Nesvat, A.P.; Stepanov, E.V.; Taranda, N.I.; Khramov, R.N.; Glinushkin, A. Effect of visible light on biological objects: Physiological and pathophysiological aspects. Phys. Wave Phenom. 2017, 25, 207-213. [CrossRef]

4. Cook, R.; Calvin, L. Greenhouse Tomatoes Change the Dynamics of the North American Fresh Tomato Industry; Economic Research Report Number 2, Economic Research Service; US Department of Agriculture: Rome, Italy, 2005. Available online: https: //www.ers.usda.gov/webdocs / publications/45465/15309_err2_1_.pdf?v=4201.2 (accessed on 12 December 2021).

5. Ramankutty, N.; Evan, A.T.; Monfreda, C.; Foley, J.A. Farming the planet: 1. Geographic distribution of global agricultural lands in the year 2000. Glob. Biogeochem. Cycles 2008, 22, 22. [CrossRef]

6. Vos, R.; Bellu, L.; Stamoulis, K.; Haight, B. The Future of Food and Agriculture-Trends and Challenges; Food and Agriculture Organisation of the United Nations: Rome, Italy, 2017.

7. Bot, G.; Van De Braak, N.; Challa, H.; Hemming, S.; Rieswijk, T.; Van Straten, G.; Verlodt, I. The solar greenhouse: State of the art in energy saving and sustainable energy supply. Acta Hortic. 2005, 691, 501-508. [CrossRef]

8. Barbosa, G.L.; Gadelha, F.D.A.; Kublik, N.; Proctor, A.; Reichelm, L.; Weissinger, E.; Wohlleb, G.M.; Halden, R.U. Comparison of Land, Water, and Energy Requirements of Lettuce Grown Using Hydroponic vs. Conventional Agricultural Methods. Int. J. Environ. Res. Public Health 2015, 12, 6879-6891. [CrossRef]

9. Nadal, A.; Llorach-Massana, P.; Cuerva, E.; López-Capel, E.; Montero, J.I.; Josa, A.; Rieradevall, J.; Royapoor, M. Buildingintegrated rooftop greenhouses: An energy and environmental assessment in the mediterranean context. Appl. Energy 2017, 187, 338-351. [CrossRef]

10. Kitai, A. Luminescent Materials and Applications; John Wiley \& Sons: Hoboken, NJ, USA, 2008; Volume 25.

11. Mahata, M.; Hofsäss, H.; Vetter, U.; Thirumalai, J. Luminescence-An Outlook on the Phenomena and Their Applications; Intechopen: London, UK, 2016; pp. 109-131.

12. Liu, N.; Chen, X.; Sun, X.; Sun, X.; Shi, J. Persistent luminescence nanoparticles for cancer theranostics application. J. Nanobiotechnol. 2021, 19, 1-24. [CrossRef]

13. Hoffman, A.; Atreya, R.; Rath, T.; Neurath, M.F. Use of Fluorescent Dyes in Endoscopy and Diagnostic Investigation. Visc. Med. 2020, 36, 95-103. [CrossRef] [PubMed]

14. Hong, G.; Antaris, A.L.; Dai, H. Near-infrared fluorophores for biomedical imaging. Nat. Biomed. Eng. 2017, 1, 1-22. [CrossRef]

15. Zhao, Y.; Wang, X.; Zhang, Y.; Li, Y.; Yao, X. Optical temperature sensing of up-conversion luminescent materials: Fundamentals and progress. J. Alloy. Compd. 2020, 817, 152691. [CrossRef] 
16. Becidyan, A.N. Luminescent pigments in security applications. Color Res. Appl. 1995, 20, 124-130. [CrossRef]

17. Schelokov, R. Polysvetanes and polysvetane effect. Her. Russ. Acad. Sci 1986, 10, 50-55.

18. Palkina, K.; Kuz'mina, N.; Strashnova, S.; Zaitsev, B.; Koval'chukova, O.; Nikitin, S.; Goncharov, O.; Schelokov, R. Synthesis and structure of the 2-Amino-3-Hydroxypyridine complexes with trivalent praseodymium, neodymium, samarium, and europium nitrates: Crystal structure of Tris (2-Amino-3-Hydroxypyridine) trinitratosamarium (III) monohydrate. Rus. J. Inorg. Chem. 2000, 45, 515-520.

19. Pogreb, R.; Finkelshtein, B.; Shmukler, Y.; Musina, A.; Popov, O.; Stanevsky, O.; Yitzchaik, S.; Gladkikh, A.; Shulzinger, A.; Streltsov, V.; et al. Low-density polyethylene films doped with europium(III) complex: Their properties and applications. Polym. Adv. Technol. 2004, 15, 414-418. [CrossRef]

20. Hemming, S.; Van Os, E.; Hemming, J.; Dieleman, J. The effect of new developed fluorescent greenhouse films on the growth of Fragaria $x$ ananassa 'Elsanta'. Eur. J. Hortic. Sci. 2006, 71, 145-154.

21. Ziessel, R.; Diring, S.; Kadjane, P.; Charbonnière, L.; Retailleau, P.; Philouze, C. Highly efficient blue photoexcitation of europium in a bimetallic Pt-Eu complex. Chem. As. J. 2007, 2, 975-982. [CrossRef]

22. Fitzmorris, B.C.; Pu, Y.-C.; Cooper, J.K.; Lin, Y.-F.; Hsu, Y.-J.; Li, Y.; Zhang, J.Z. Optical Properties and Exciton Dynamics of Alloyed Core/Shell/Shell Cd1-x Zn x Se/ZnSe/ZnS Quantum Dots. ACS Appl. Mater. Interfaces 2013, 5, 2893-2900. [CrossRef]

23. Nguyen, A.T.; Lin, W.-H.; Lu, Y.-H.; Chiou, Y.-D.; Hsu, Y.-J. First demonstration of rainbow photocatalysts using ternary Cd1-xZnxSe nanorods of varying compositions. Appl. Catal. A Gen. 2014, 476, 140-147. [CrossRef]

24. Pu, Y.-C.; Chen, W.-T.; Fang, M.-J.; Chen, Y.-L.; Tsai, K.-A.; Lin, W.-H.; Hsu, Y.-J. Au-Cd 1- x Zn x S core-alloyed shell nanocrystals: Boosting the interfacial charge dynamics by adjusting the shell composition. J. Mater. Chem. A 2018, 6, 17503-17513. [CrossRef]

25. Parrish, C.H., II; Hebert, D.; Jackson, A.; Ramasamy, K.; McDaniel, H.; Giacomelli, G.A.; Bergren, M.R. Optimizing spectral quality with quantum dots to enhance crop yield in controlled environments. Commun. Biol. 2021, 4, 124. [CrossRef]

26. Simakin, A.V.; Ivanyuk, V.V.; Dorokhov, A.S.; Gudkov, S.V. Photoconversion Fluoropolymer Films for the Cultivation of Agricultural Plants Under Conditions of Insufficient Insolation. Appl. Sci. 2020, 10, 8025. [CrossRef]

27. Gudkov, S.V.; Simakin, A.V.; Bunkin, N.F.; Shafeev, G.A.; Astashev, M.E.; Glinushkin, A.P.; Grinberg, M.A.; Vodeneev, V.A Development and application of photoconversion fluoropolymer films for greenhouses located at high or polar latitudes. J. Photochem. Photobiol. B Biol. 2020, 213, 112056. [CrossRef] [PubMed]

28. Ivanyuk, V.V.; Shkirin, A.V.; Belosludtsev, K.N.; Dubinin, M.V.; Kozlov, V.A.; Bunkin, N.F.; Dorokhov, A.S.; Gudkov, S.V. Influence of Fluoropolymer Film Modified with Nanoscale Photoluminophor on Growth and Development of Plants. Front. Phys. 2020, 8, 616040. [CrossRef]

29. Ovsyankin, V.; Feofilov, P. Mechanism of summation of electronic excitations in activated crystals. Sov. J. Exp. Theor. Phys. Lett. 1966, 3, 322.

30. Auzel, F. Quantum counter by energy transfer from $\mathrm{Yb3}+$ to $\mathrm{Tm} 3+$ in a mixed tungstate and a germanate glass. CR Acad. Sci. (Paris) 1966, 263, 819-821.

31. Dieke, G.H.; Crosswhite, H.M. The Spectra of the Doubly and Triply Ionized Rare Earths. Appl. Opt. 1963, 2, 675-686. [CrossRef]

32. Bloembergen, N. Solid State Infrared Quantum Counters. Phys. Rev. Lett. 1959, 2, 84-85. [CrossRef]

33. Auzel, F. Upconversion and Anti-Stokes Processes with $\mathrm{f}$ and d Ions in Solids. Chem. Rev. 2004, 104, 139-174. [CrossRef] [PubMed]

34. Ritter, B.; Haida, P.; Krahl, T.; Scholz, G.; Kemnitz, E. Core-shell metal fluoride nanoparticles via fluorolytic sol-gel synthesis-a fast and efficient construction kit. J. Mater. Chem. C 2017, 5, 5444-5450. [CrossRef]

35. Reig, D.S.; Grauel, B.; Konyushkin, V.A.; Nakladov, A.N.; Fedorov, P.P.; Busko, D.; Howard, I.A.; Richards, B.S.; Resch-Genger, U.; Kuznetsov, S.; et al. Upconversion properties of SrF2:Yb3+,Er3+ single crystals. J. Mater. Chem. C 2020, 8, 4093-4101. [CrossRef]

36. Falin, M.L.; I Gerasimov, K.; A Latypov, V.; Leushin, A.M. Electron paramagnetic resonance and optical spectroscopy of Yb3 ions in SrF2and BaF2; an analysis of distortions of the crystal lattice near Yb3. J. Phys. Condens. Matter 2003, 15, 2833-2847. [CrossRef]

37. Madirov, E.I.; Konyushkin, V.A.; Nakladov, A.N.; Fedorov, P.P.; Bergfeldt, T.; Busko, D.; Howard, I.A.; Richards, B.S.; Kuznetsov, S.V.; Turshatov, A. An up-conversion luminophore with high quantum yield and brightness based on BaF2:Yb3+,Er3+ single crystals. J. Mater. Chem. C 2021, 9, 3493-3503. [CrossRef]

38. Würth, C.; Fischer, S.; Grauel, B.; Alivisatos, A.P.; Resch-Genger, U. Quantum Yields, Surface Quenching, and Passivation Efficiency for Ultrasmall Core/Shell Upconverting Nanoparticles. J. Am. Chem. Soc. 2018, 140, 4922-4928. [CrossRef] [PubMed]

39. Kaiser, M.; Würth, C.; Kraft, M.; Hyppänen, I.; Soukka, T.; Resch-Genger, U. Power-dependent upconversion quantum yield of NaYF4:Yb3+,Er3+ nano- and micrometer-sized particles - Measurements and simulations. Nanoscale 2017, 9, 10051-10058. [CrossRef]

40. Sukhova, E.; Sukhov, V. Electrical Signals, Plant Tolerance to Actions of Stressors, and Programmed Cell Death: Is Interaction Possible? Plants 2021, 10, 1704. [CrossRef]

41. Demotes-Mainard, S.; Péron, T.; Corot, A.; Bertheloot, J.; Le Gourrierec, J.; Pelleschi-Travier, S.; Crespel, L.; Morel, P.; HuchéThélier, L.; Boumaza, R.; et al. Plant responses to red and far-red lights, applications in horticulture. Environ. Exp. Bot. 2016, 121, 4-21. [CrossRef]

42. Huché-Thélier, L.; Crespel, L.; Le Gourrierec, J.; Morel, P.; Sakr, S.; Leduc, N. Light signaling and plant responses to blue and UV radiations-Perspectives for applications in horticulture. Environ. Exp. Bot. 2016, 121, 22-38. [CrossRef]

43. McCree, K. The action spectrum, absorptance and quantum yield of photosynthesis in crop plants. Agric. Meteorol. 1971, 9, 191-216. [CrossRef] 
44. Trouwborst, G.; Hogewoning, S.W.; van Kooten, O.; Harbinson, J.; van Ieperen, W. Plasticity of photosynthesis after the 'red light syndrome'in cucumber. Environ. Exp. Bot. 2016, 121, 75-82. [CrossRef]

45. Hogewoning, S.; Trouwborst, G.; Maljaars, H.; Poorter, H.; Van Ieperen, W.; Harbinson, J. Blue light dose-responses of leaf photosynthesis, morphology, and chemical composition of Cucumis sativus grown under different combinations of red and blue light. J. Exp. Bot. 2010, 61, 3107-3117. [CrossRef]

46. Van Ieperen, W.; Savvides, A.; Fanourakis, D. Red and blue light effects during growth on hydraulic and stomatal conductance in leaves of young cucumber plants. In Proceedings of the VII International Symposium on Light in Horticultural Systems 956 , Wageningen, The Netherlands, 15-18 October 2012; pp. 223-230.

47. Nanya, K.; Ishigami, Y.; Hikosaka, S.; Goto, E. Effects of blue and red light on stem elongation and flowering of tomato seedlings. In Proceedings of the VII International Symposium on Light in Horticultural Systems 956, Wageningen, The Netherlands, 15-18 October 2012; pp. 261-266.

48. Savvides, A.; Fanourakis, D.; van Ieperen, W. Co-ordination of hydraulic and stomatal conductances across light qualities in cucumber leaves. J. Exp. Bot. 2012, 63, 1135-1143. [CrossRef]

49. Sun, J.; Nishio, J.N.; Vogelmann, T.C. Green Light Drives CO2 Fixation Deep within Leaves. Plant Cell Physiol. 1998, 39, 1020-1026. [CrossRef]

50. Terashima, I.; Fujita, T.; Inoue, T.; Chow, W.S.; Oguchi, R. Green Light Drives Leaf Photosynthesis More Efficiently than Red Light in Strong White Light: Revisiting the Enigmatic Question of Why Leaves are Green. Plant Cell Physiol. 2009, 50, 684-697. [CrossRef] [PubMed]

51. Paradiso, R.; Meinen, E.; Snel, J.F.; De Visser, P.; Van Ieperen, W.; Hogewoning, S.W.; Marcelis, L.F. Spectral dependence of photosynthesis and light absorptance in single leaves and canopy in rose. Sci. Hortic. 2011, 127, 548-554. [CrossRef]

52. Pak, A.M.; Ermakova, J.A.; Kuznetsov, S.V.; Ryabova, A.V.; Pominova, D.V.; Voronov, V.V. Efficient visible range SrF2:Yb:Er- and SrF2:Yb:Tm-based up-conversion luminophores. J. Fluor. Chem. 2017, 194, 16-22. [CrossRef]

53. Dual-PAM-100 Measuring System for Simultaneous Assessment of P700 and Chlorophyll Fluorescence, Instrument Description and Instructions for Users 2.151/07.06 2. Heinz Walz GmbH. DUAL-PAM_1e.doc. 2006. Available online: https:/ /www.walz. com/files/downloads/manuals/dual-pam-100/Dual-PAM_1e.pdf (accessed on 12 December 2021).

54. Korneev, D.Y. Information possibilities of chlorophyll fluorescence induction method. Ky. Altpress 2002.

55. Campbell, D.; Wu, C.A.; Travers, S.E. Photosynthetic and growth responses of reciprocal hybrids to variation in water and nitrogen availability. Am. J. Bot. 2010, 97, 925-933. [CrossRef]

56. Savchenko, T.; Yanykin, D.; Khorobrykh, A.; Terentyev, V.; Klimov, V.; Dehesh, K. The hydroperoxide lyase branch of the oxylipin pathway protects against photoinhibition of photosynthesis. Planta 2017, 245, 1179-1192. [CrossRef]

57. Labbe, C.; Doualan, J.; Camy, P.; Moncorgé, R.; Thuau, M. The $2.8 \mu \mathrm{m}$ laser properties of Er3+ doped CaF2 crystals. Opt. Commun. 2002, 209, 193-199. [CrossRef]

58. Camy, P.; Doualan, J.-L.; Benayad, A.; Von Edlinger, M.; Ménard, V.; Moncorgé, R. Comparative spectroscopic and laser properties of $\mathrm{Yb}$ 3+-doped CaF 2, SrF 2 and BaF 2 single crystals. Appl. Phys. B 2007, 89, 539-542. [CrossRef]

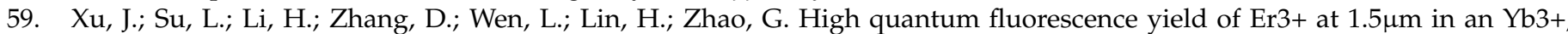
Ce3+-codoped CaF2 crystal. Opt. Mater. 2007, 29, 932-935. [CrossRef]

60. Druon, F.; Ricaud, S.; Papadopoulos, D.N.; Pellegrina, A.; Camy, P.; Doualan, J.L.; Moncorgé, R.; Courjaud, A.; Mottay, E.; Georges, P. On Yb: CaF 2 and $\mathrm{Yb}$ : SrF 2: Review of spectroscopic and thermal properties and their impact on femtosecond and high power laser performance. Opt. Mater. Express 2011, 1, 489-502. [CrossRef]

61. Ma, W.; Su, L.; Xu, X.; Wang, J.; Jiang, D.; Zheng, L.; Fan, X.; Li, C.; Liu, J.; Xu, J. Effect of erbium concentration on spectroscopic properties and $279 \mu \mathrm{m}$ laser performance of Er:CaF_2 crystals. Opt. Mater. Express 2016, 6, 409-415. [CrossRef]

62. Kreslavski, V.D.; Los, D.A.; Schmitt, F.-J.; Zharmukhamedov, S.K.; Kuznetsov, V.V.; Allakhverdiev, S.I. The impact of the phytochromes on photosynthetic processes. Biochim. et Biophys. Acta (BBA)-Bioenerg. 2018, 1859, 400-408. [CrossRef]

63. Cao, K.; Yu, J.; Xu, D.; Ai, K.; Bao, E.; Zou, Z. Exposure to lower red to far-red light ratios improve tomato tolerance to salt stress BMC Plant Biol. 2018, 18, 92. [CrossRef] [PubMed]

64. Khramov, R.N.; Kreslavski, V.D.; Svidchenko, E.A.; Surin, N.M.; Kosobryukhov, A.A. Influence of photoluminophore-modified agro textile spunbond on growth and photosynthesis of cabbage and lettuce plants. Opt. Express 2019, 27, 31967-31977. [CrossRef] [PubMed]

65. Zhang, Z.; Zhao, Z.; Lu, Y.; Wang, D.; Wang, C.; Li, J. One-Step Synthesis of Eu ${ }^{3+}$-Modified Cellulose Acetate Film and Light Conversion Mechanism. Polymers 2020, 13, 113. [CrossRef] [PubMed]

66. Wu, W.; Zhang, Z.; Dong, R.; Xie, G.; Zhou, J.; Wu, K.; Zhang, H.; Cai, Q.; Lei, B. Characterization and properties of a Sr2Si5N8:Eu2+-based light-conversion agricultural film. J. Rare Earths 2020, 38, 539-545. [CrossRef]

67. Kalaji, H.M.; Dąbrowski, P.; Cetner, M.D.; Samborska, I.A.; Łukasik, I.; Brestic, M.; Zivcak, M.; Tomasz, H.; Mojski, J.; Kociel, H.; et al. A comparison between different chlorophyll content meters under nutrient deficiency conditions. J. Plant Nutr. 2017, 40, 1024-1034. [CrossRef]

68. Novoplansky, A.; Sachs, T.; Cohen, D.; Bar, R.; Bodenheimer, J.; Reisfeld, R. Increasing plant productivity by changing the solar spectrum. Sol. Energy Mater. 1990, 21, 17-23. [CrossRef]

69. Ke-Li, Z.; Liang-Jie, Y.; Mei-Yun, X.; You-Zu, Y.; Ju-Tang, S. The application of lights-conversed polyethylene film for agriculture. Wuhan Univ. J. Nat. Sci. 2002, 7, 365-367. [CrossRef] 
70. Yoon, H.I.; Kim, J.H.; Park, K.S.; Namgoong, J.W.; Hwang, T.G.; Kim, J.P.; Son, J.E. Quantitative methods for evaluating the conversion performance of spectrum conversion films and testing plant responses under simulated solar conditions. Hortic. Environ. Biotechnol. 2020, 61, 999-1009. [CrossRef]

71. Yoon, H.; Kang, J.; Kang, W.; Son, J. Subtle changes in solar radiation under a green-to-red conversion film affect the photosynthetic performance and chlorophyll fluorescence of sweet pepper. Photosynthetica 2020, 58, 1107-1115. [CrossRef]

72. Minich, A.; Minich, I.; Shaitarova, O.; Permyakova, N.; Zelenchukova, N.; Ivanitskiy, A.; Filatov, D.; Ivlev, G. Vital activity of Lactuca sativa and soil microorganisms under fluorescent films. TSPU Bull. 2011, 8, 78-84. Available online: https://vestnik.tspu. edu.ru/files/vestnik/PDF/articles/minich_a._s._78_84_8_110_2011.pdf (accessed on 12 December 2021).

73. Schettini, E.; De Salvador, F.R.; Scarascia-Mugnozza, G.; Vox, G. Radiometric properties of photoselective and photoluminescent greenhouse plastic films and their effects on peach and cherry tree growth. J. Hortic. Sci. Biotechnol. 2011, 86, 79-83. [CrossRef]

74. Nishimura, Y.; Wada, E.; Fukumoto, Y.; Aruga, H.; Shimoi, Y. The effect of spectrum conversion covering film on cucumber in soilless culture. In Proceedings of the VII International Symposium on Light in Horticultural Systems 956, Wageningen, The Netherlands, 15-18 October 2012; pp. 481-487.

75. Sánchez-Lanuza, M.B.; Menéndez-Velázquez, A.; Peñas-Sanjuan, A.; Navas-Martos, F.J.; Lillo-Bravo, I.; Delgado-Sánchez, J.-M. Advanced Photonic Thin Films for Solar Irradiation Tuneability Oriented to Greenhouse Applications. Materials 2021, 14, 2357. [CrossRef]

76. Hamada, K.; Shimasaki, K.; Ogata, T.; Nishimura, Y.; Nakamura, K.; Oyama-Egawa, H.; Yoshida, K. Effects of Spectral Composition Conversion Film and Plant Growth Regulators on Proliferation of Cymbidium Protocorm Like Body (PLB) Cultured In Vitro. Environ. Control. Biol. 2010, 48, 127-132. [CrossRef]

77. Liu, X.; Chang, T.; Guo, S.; Xu, Z.; Li, J. Effect of different light quality of LED on growth and photosynthetic character in cherry tomato seedling. In Proceedings of the VI International Symposium on Light in Horticulture 907, Tsukuba, Japan, 15-19 November 2009; pp. 325-330.

78. Edser, C. Auto applications drive commercialization of nanocomposites. Plast. Addit. Compd. 2002, 4, 30-33. [CrossRef]

79. Rodríguez, R.; Bañón, S.; Franco, J.; Fernández, J.; Salmerón, A.; Espí, E.; González, A. Strawberry and cucumber cultivation under fluorescent photoselective plastic films cover. In Proceedings of the VI International Symposium on Protected Cultivation in Mild Winter Climate: Product and Process Innovation 614, Ragusa-Sicily, Italy, 5-8 March 2002; pp. 407-413.

80. De Salvador, F.; Scarascia-Mugnozza, G.; Vox, G.; Schettini, E.; Mastrorilli, M.; Jaoudé, M.B. Innovative photoselective and photoluminescent plastic films for protected cultivation. Acta Hortic. 2008, 801, 115-122. [CrossRef]

81. Hidaka, K.; Yoshida, K.; Shimasaki, K.; Murakami, K.; Yasutake, D.; Kitano, M. Spectrum Conversion Film for Regulation of Plant Growth. J. Fac. Agric. Kyushu Univ. 2008, 53, 549-552. [CrossRef]

82. Yoon, H.I.; Kang, J.H.; Kim, D.; Son, J.E. Seedling Quality and Photosynthetic Characteristic of Vegetables Grown Under a Spectrum Conversion Film. J. Bio-Environ. Control 2021, 30, 110-117. [CrossRef]

83. Yongcheng, C.; Li, T.; Yang, Q.; Zhang, Y.; Zou, J.; Bian, Z.; Wen, X. UVA Radiation Is Beneficial for Yield and Quality of Indoor Cultivated Lettuce. Front. Plant Sci. 2019, 10, 1563. [CrossRef]

84. Minich, A.S.; Minich, I.B.; Zelen'Chukova, N.S.; Karnachuk, R.A.; Golovatskaya, I.F.; Efimova, M.V.; Raida, V.S. The role of low intensity red luminescent radiation in the control of Arabidopsis thaliana morphogenesis and hormonal balance. Russ. J. Plant Physiol. 2006, 53, 762-767. [CrossRef]

85. Marulanda, A.; Barea, J.M.; Azcón, R. Stimulation of Plant Growth and Drought Tolerance by Native Microorganisms (AM Fungi and Bacteria) from Dry Environments: Mechanisms Related to Bacterial Effectiveness. J. Plant Growth Regul. 2009, 28, 115-124. [CrossRef]

86. Jursinic, P. Effects of hydroxylamine and silicomolybdate on the decay in delayed light emission in the 6-100 $\mu$ s range after a single 10 ns flash in pea thylakoids. Photosynth. Res. 1982, 3, 161-177. [CrossRef] [PubMed]

87. Tognetti, R.; Minotta, G.; Pinzauti, S.; Michelozzi, M.; Borghetti, M. Acclimation to changing light conditions of long-term shade-grown beech (Fagus sylvatica L.) seedlings of different geographic origins. Trees 1998, 12, 326-333. [CrossRef]

88. Kyle, D.J.; Ohad, I.; Arntzen, C.J. Membrane protein damage and repair: Selective loss of a quinone-protein function in chloroplast membranes. Proc. Natl. Acad. Sci. USA 1984, 81, 4070-4074. [CrossRef] [PubMed]

89. Ohad, I.; Kyle, D.J.; Arntzen, C.J. Membrane protein damage and repair: Removal and replacement of inactivated 32-kilodalton polypeptides in chloroplast membranes. J. Cell Biol. 1984, 99, 481-485. [CrossRef] 